Pacific Journal of Mathematic 


\section{THE VOLUME CUT OFF A SIMPLEX}

BY A HALF-SPACE

\section{LeON Gerber}

A formula for the volume cut off an $n$-dimensional simplex by a half-space has immediate application in probability theory. This note presents a derivation of such a formula in a short and completely elementary way and also yields the moments of this volume about the coordinate hyperplanes, and the volumes cut off the lower dimensional faces of the simplex and their moments.

Before stating our results we introduce some notation. The "minus function" $(x)_{-}^{k}$ equals $x^{k}$ if $x<0$ and is zero otherwise. The $n$th divided difference of a real-valued function $f(x)$ is the symmetric function of $n+1$ arguments defined inductively by

$$
\begin{aligned}
& D\left\{f(x): x_{0}, x_{1}\right\}=\frac{f\left(x_{0}\right)-f\left(x_{1}\right)}{x_{0}-x_{1}}, \\
& D\left\{f(x): x_{0}, x_{1}, \cdots, x_{n}\right\} \\
& \quad=\frac{D\left\{f(x): x_{0}, x_{1}, \cdots, x_{n-1}\right\}-D\left\{f(x): x_{n}, x_{1}, \cdots, x_{n-1}\right\}}{x_{0}-x_{n}} .
\end{aligned}
$$

If $x_{0}=x_{n}$ we define

$$
D\left\{f(x): x_{0}, x_{1}, \cdots, x_{n-1}, x_{0}\right\}=\frac{\partial}{\partial x_{0}} D\left\{f(x): x_{0}, x_{1}, \cdots, x_{n-1}\right\}
$$

and similarly for all repeated arguments. The algorithm of Varsi [1, p 317] enables the calculation of such differences for $f(x)=(x)_{-}^{k}$ without the use of limiting processes. A proof of the symmetry and other elementary properties of divided differences may be found in [4].

The unit $n$-simplex with vertices $a_{0}=(0, \cdots 0), a_{1}=(1,0, \cdots, 0)$, $\cdots, \boldsymbol{a}_{n}=(0, \cdots, 0,1)$ will be denoted by $\mathscr{A}_{n}$, and $\mathscr{B}_{n}$ will denote an $n$-simplex with vertices $\boldsymbol{b}_{0}, \boldsymbol{b}_{1}, \cdots, \boldsymbol{b}_{n}$ where $\boldsymbol{b}_{i}$ has cartesian coordinates $\left(b_{i 1}, \cdots, b_{i n}\right)$. We denote by $\mathscr{B}_{k}$ the $k$-face of $\mathscr{B}_{n}$ with vertices $\boldsymbol{b}_{0}$, $\boldsymbol{b}_{1}, \cdots, \boldsymbol{b}_{k}$. The $n$-volume ( $n$-dimensional volume) of $\mathscr{B}_{n}$ and the $k$ volume of $\mathscr{B}_{k}, k=1, \cdots, n$ are given by

$$
v_{n}\left(\mathscr{B}_{n}\right)=\frac{1}{n !}\left|\begin{array}{cc}
1 & b_{01} \cdots b_{0 n} \\
& \cdots \\
1 & b_{n 1} \cdots b_{n n}
\end{array}\right|,
$$




$$
v_{k}\left(\mathscr{B}_{k}\right)=\frac{1}{k !}\left|\begin{array}{ccccc}
0 & 1 & 1 & \cdots & 1 \\
1 & \boldsymbol{b}_{0} \cdot \boldsymbol{b}_{0} & \boldsymbol{b}_{0} \cdot \boldsymbol{b}_{1} & \cdots & \boldsymbol{b}_{0} \cdot \boldsymbol{b}_{k} \\
& & \cdots & \\
1 & \boldsymbol{b}_{k} \cdot \boldsymbol{b}_{0} & \boldsymbol{b}_{k} \cdot \boldsymbol{b}_{1} & \cdots & \boldsymbol{b}_{k} \cdot \boldsymbol{b}_{k}
\end{array}\right|^{1 / 2}
$$

We are now ready for our main result.

THEOREM. Consider a linear function $L(\boldsymbol{x})=a_{0}+a_{1} x_{1}+\cdots+$ $a_{n} x_{n}$ and the half-space $\mathscr{H}$ defined by $L(\boldsymbol{x}) \leqq 0$. Let $p$ be any nonnegative integer. Then for $k=1,2, \cdots, n$ :

1. $\int_{\mathscr{O}_{k}}[L(\boldsymbol{x})]^{p} d v_{k}$

$$
=\frac{k ! p !}{(k+p) !} v_{k}\left(\mathscr{B}_{k}\right) D\left\{x^{k+p}: L\left(\boldsymbol{b}_{0}\right), L\left(\boldsymbol{b}_{1}\right), \cdots, L\left(\boldsymbol{b}_{k}\right)\right\} .
$$

2. The k-volume cut off the k-simplex $\mathscr{B}_{k}$ by $\mathscr{\mathscr { C }}$ is given by

$$
v_{k}\left(\mathscr{B}_{k} \cap \mathscr{C}\right)=v_{k}\left(\mathscr{B}_{k}\right) D\left\{(x)_{-}^{k}: L\left(\boldsymbol{b}_{0}\right), L\left(\boldsymbol{b}_{1}\right), \cdots, L\left(\boldsymbol{b}_{k}\right)\right\} \text {. }
$$

3. If $p=p_{1}+\cdots+p_{n}$, then the $p$ th mixed moment of $\mathscr{B}_{k} \cap \mathscr{H}$ about the coordinate hyperplanes is given by

$$
\begin{aligned}
\int_{\mathscr{B}_{k} \cap \mathscr{e}} x_{1}^{p_{1}} \cdots x_{n}^{p_{n}} d v_{k} \\
\quad=\frac{k !}{(k+p) !} v_{k}\left(\mathscr{B}_{k}\right) \frac{\partial^{p}}{\partial a_{1}^{p_{1}} \cdots \partial a_{n}^{p_{n}}} D\left\{(x)_{-}^{k+p}: L\left(\boldsymbol{b}_{0}\right), L\left(\boldsymbol{b}_{1}\right), \cdots, L\left(\boldsymbol{b}_{k}\right)\right\} .
\end{aligned}
$$

Proof. Our first observation is that for all $p$

$$
\begin{gathered}
\int_{\mathscr{A}_{n}}\left[c_{0}+\left(c_{1}-c_{0}\right) y_{1}+\cdots+\left(c_{n}-c_{0}\right) y_{n}\right]^{p} d y \\
=\frac{p !}{(n+p) !}\left\{x^{n+p}: c_{0}, c_{1}, \cdots, c_{n}\right\}
\end{gathered}
$$

where $\int_{\mathscr{S}_{n}} f(\boldsymbol{y}) d \boldsymbol{y}$ means $\int_{y_{1}=0}^{1} \int_{y_{2}=0}^{1-y_{1}} \cdots \int_{y_{n}=0}^{1-y_{1}-\cdots-y_{n-1}} f(\boldsymbol{y}) d y_{n} \cdots d y_{1}$. The The proof is by a straightforward induction on $n$ when the $c_{i}$ are distinct, and by continuity otherwise.

To prove part 1 for $k=n$ consider the transformation defined by

$$
\begin{gathered}
x_{1}=b_{01}+\left(b_{11}-b_{01}\right) y_{1}+\cdots+\left(b_{n 1}-b_{01}\right) y_{n} \\
\cdots \\
x_{n}=b_{0 n}+\left(b_{1 n}-b_{0 n}\right) y_{1}+\cdots+\left(b_{n n}-b_{0 n}\right) y_{n},
\end{gathered}
$$

so when $\boldsymbol{y}=\boldsymbol{a}_{i}$ then $\boldsymbol{x}=\boldsymbol{b}_{i}, i=0,1, \cdots, n$. Note that the Jacobian of this transformation is 


$$
\left|\begin{array}{c}
b_{11}-b_{01} \cdots b_{n 1}-b_{01} \\
\cdots \\
b_{1 n}-b_{0 n} \cdots b_{n n}-b_{0 n}
\end{array}\right|=\left|\begin{array}{ccc}
1 & 1 \cdots & 1 \\
b_{01} & b_{11} \cdots & b_{n 1} \\
& \cdots \\
b_{0 n} & b_{1 n} \cdots b_{n n}
\end{array}\right|=n ! v_{n}\left(\mathscr{B}_{n}\right)
$$

Then

$$
\begin{aligned}
\int_{\mathscr{G}_{n}} & {\left[L\left(x_{1}, \cdots, x_{n}\right)\right]^{p} d x_{1} \cdots d x_{n} / n ! v_{n}\left(\mathscr{B}_{n}\right) } \\
& =\int_{\mathscr{A}_{n}}\left\{L\left(\boldsymbol{b}_{0}\right)+\left[\left[L\left(\boldsymbol{b}_{1}\right)-L\left(\boldsymbol{b}_{0}\right)\right] y_{1}+\cdots+\left[L\left(\boldsymbol{b}_{n}\right)-L\left(\boldsymbol{b}_{0}\right) y_{n}\right]\right\}^{p} d \boldsymbol{y}\right. \\
& =\frac{p !}{(n+p) !} D\left\{x^{n+p}: L\left(\boldsymbol{b}_{0}\right), L\left(\boldsymbol{b}_{1}\right), \cdots, L\left(\boldsymbol{b}_{n}\right)\right\} .
\end{aligned}
$$

For the case $1 \leqq k \leqq n-1$ we may assume $\mathscr{B}_{k}$ is not orthogonal to the coordinate $k$-flat $\mathscr{F}$ defined by $x_{k+1}=\cdots=x_{n}=0$ (since $\mathscr{B}_{k}$ cannot be orthogonal to all $\left(\begin{array}{l}n \\ k\end{array}\right)$ such $k$-flats) so $\mathscr{B}_{k}$ can be defined by linear equations in the form

$$
x_{j}=M_{j}\left(x_{1}, \cdots, x_{k}\right), \quad j=k+1, \cdots, n .
$$

Let $\boldsymbol{x}^{*}$ denote the orthogonal projection of a point $\boldsymbol{x}$ on $\mathscr{F}$ and let

$$
L^{*}\left(x_{1}, \cdots, x_{k}\right)=L\left(x_{1}, \cdots, x_{k}, M_{k+1}\left(x_{1}, \cdots, x_{k}\right), \cdots, M_{n}\left(x_{1} \cdots, x_{k}\right)\right)
$$

so for any point $\boldsymbol{x}$ of $\mathscr{B}_{k}$ we have $L^{*}\left(\boldsymbol{x}^{*}\right)=L(\boldsymbol{x})$, and in particular, $L^{*}\left(\boldsymbol{b}_{i}^{*}\right)=L\left(\boldsymbol{b}_{i}\right), i=0,1, \cdots, k$. Since orthogonal projection shrinks $d v_{k}$ and $v_{k}\left(\mathscr{B}_{k}\right)$ by the same factor, we have

$$
\begin{aligned}
\int_{\mathscr{B}_{k}}[L(\boldsymbol{x})]^{p} d v_{k} / v_{k}\left(\mathscr{B}_{k}\right) & =\int_{\mathscr{G}_{k}^{*}}\left[L^{*}\left(x_{1}, \cdots, x_{k}\right)\right]^{p} d x_{1} \cdots d x_{k} / v_{k}\left(\mathscr{B}_{k}^{*}\right) \\
& =\frac{k ! p !}{(k+p) !} D\left\{x^{k+p}: L^{*}\left(\boldsymbol{b}_{0}^{*}\right), L^{*}\left(\boldsymbol{b}_{1}^{*}\right), \cdots, L^{*}\left(\boldsymbol{b}_{k}^{*}\right)\right\}
\end{aligned}
$$

which completes the proof of the first result.

Now it is easy to verify that if $a \neq 0$ then

$$
\int(a x+b)_{-}^{p} d x=\frac{\left.a x+b)^{p+1}\right)}{a(p+1)}+c .
$$

This means that the minus function integrates formally like a polynomial and we may conclude that

$$
\int_{\mathscr{O}_{k}}[L(\boldsymbol{x})]_{-p}^{p} d v_{k}=\frac{k ! p !}{(k+p) !} v_{k}\left(\mathscr{B}_{k}\right) D\left\{(x)_{-}^{p+k}: L\left(\boldsymbol{b}_{0}\right), L\left(\boldsymbol{b}_{1}\right), \cdots, L\left(\boldsymbol{b}_{k}\right)\right\} .
$$

In particular, since $\boldsymbol{x} \in \mathscr{H}$ if and only if $L(\boldsymbol{x}) \leqq 0$ we have

$$
v_{k}\left(\mathscr{B}_{k} \cap \mathscr{C}\right)=\int_{\mathscr{B}_{k}}[L(\boldsymbol{x})]_{-}^{0} d v_{k}=v_{k}\left(\mathscr{B}_{k}\right) D\left\{(x)_{-}^{k}: L\left(\boldsymbol{b}_{0}\right), L\left(\boldsymbol{b}_{1}\right), \cdots, L\left(b_{k}\right)\right\}
$$

which is our second result. 
Our final result comes from the observation that

$$
\int_{\mathscr{B}_{k} \cap \mathscr{C}} x_{1}^{p_{1}} \cdots x_{n}^{p_{n}} d v_{k}=\frac{1}{p !} \int_{\mathscr{A}_{k}} \frac{\partial^{p}}{\partial a_{1}^{p_{1}} \cdots \partial{a_{n}^{p}}_{n}^{p_{n}}}[L(\boldsymbol{x})]_{-}^{p} d v_{k} .
$$

Corollary. Let $\mathscr{H}$ be the half-space defined by $a_{0}+a_{1} x_{1}+\cdots+$ $a_{n} x_{n} \leqq 0$. Then

$$
\begin{aligned}
v_{n}\left(\mathscr{A}_{n} \cap \mathscr{H}\right) / v_{n}\left(\mathscr{A}_{n}\right) & =D\left\{(x)_{-}^{n}: a_{0}, a_{0}+a_{1}, \cdots, a_{0}+a_{n}\right\} \\
& =D\left\{\left(x+a_{0}\right)_{-}^{n}: 0, a_{1}, \cdots, a_{n}\right\}
\end{aligned}
$$

where $v_{n}\left(\mathscr{A}_{n}\right)=1 / n$ ! , and

$$
v_{n-1}\left(\mathscr{A}_{n-1} \cap \mathscr{H}\right) / v_{n-1}\left(\mathscr{A}_{n-1}\right)=D\left\{\left(x+a_{0}\right)_{-}^{n-1}: a_{1}, \cdots, a_{n}\right\}
$$

where $\mathscr{A}_{n-1}$ is the $(n-1)$-face with vertices $\boldsymbol{a}_{1}, \cdots, \boldsymbol{a}_{n}$, and $v_{n-1}\left(\mathscr{A}_{n-1}\right)=$ $\sqrt{n /}(n-1)$ !

Varsi [5] discovered an algorithm equivalent to the first result of the corollary by dissecting $\mathscr{A}_{n}$ into $O\left(2^{n}\right)$ simplexes; his algorithm requires $O\left(n^{2}\right)$ computations and is hence quite efficient. Ali [1] observed that Varsi's algorithm was equivalent to divided differences and proved this result using the Fourier-Stieltjes transform; he also proved the second result of the corollary. The technique of integrating a "plus function" was used in [2] to find the volume cut off a hypercube by a half-space, a result which was obtained previously in [3, pp. 48-50] using a more elementary technique which, curiously enough, involved a density function defined on $2^{n}$ overlapping regions of space.

Added in proof. The third part of the theorem can be put in a more useful form. For example, using $L_{i}$ for $L\left(\boldsymbol{b}_{i}\right)$, the centroid $\mathscr{B}_{k} \cap \mathscr{H}$ is given by

$$
\frac{D\left\{(x)_{-}^{k+1}: L_{0}, L_{0}, L_{1}, L_{2}, \cdots, L_{k}\right\} \boldsymbol{b}_{0}+0\left\{(x)^{k+1}: L_{0}, L_{1}, L_{1}, L_{2}, \cdots, L_{k}\right\} \boldsymbol{b}_{1}+\cdots}{(k+1) D\left\{(x)_{-}^{k}: L_{0}, L_{1}, L_{2}, \cdots, L_{k}\right\}} .
$$

\section{REFERENCES}

1. M. M. Ali, Content of the frustrum of a simplex, Pacific J. Math., 48 (1973), 313-322.

2. D. L. Barrow and P. W. Smith, Spline notation applied to a volume problem, Amer. Math. Monthly, 86 (1979), 50-51.

3. M. G. Kendall, A Course in the Geometry of $n$ Dimensions, Griffin, London, 1961.

4. J. F. Steffenson, Interpolation, Williams and Wilkins, 1927.

5. G. Varsi, The Multidimensional content of the frustrum of the simplex, Pacific J. Math., 46 (1973), 303-314.

Received October 19, 1979.

ST. JOHN'S UNIVERSITY

JAMAICA, NY 11439 


\section{PACIFIC JOURNAL OF MATHEMATICS}

\section{EDITORS}

DONALD BABBITT (Managing Editor)

University of California

Los Angeles, CA 90024

Hugo RossI

University of Utah

Salt Lake City, UT 84112

C. C. MOORE and ANDREW OGG

University of California

Berkeley, CA 94720
J. DugundjI

Department of Mathematics

University of Southern California

Los Angeles, CA 90007

R. FINN and J. MILGRAM

Stanford University

Stanford, CA 94305

\section{ASSOCIATE EDITORS}
R. ARENS
E. F. BECKENBACH
B. H. NeUmanN
F. WOLF
K. YosHIDA

\section{SUPPORTING INSTITUTIONS}

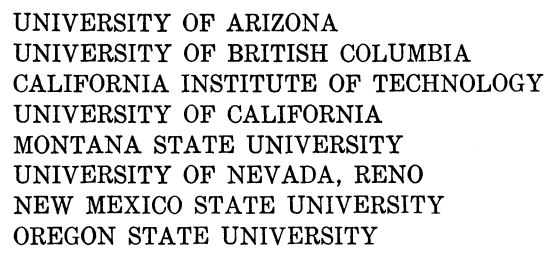

UNIVERSITY OF ARIZONA

UNIVERSITY OF BRITISH COLUMBIA CALIFORNIA INSTITUTE OF TECHNOLOGY

UNIVERSITY OF CALIFORNIA

MONTANA STATE UNIVERSITY

UNIVERSITY OF NEVADA, RENO

NEW MEXICO STATE UNIVERSITY OREGON STATE UNIVERSITY

\author{
UNIVERSITY OF OREGON \\ UNIVERSITY OF SOUTHERN CALIFORNIA \\ STANFORD UNIVERSITY \\ UNIVERSITY OF HAWAII \\ UNIVERSITY OF TOKYO \\ UNIVERSITY OF UTAH \\ WASHINGTON STATE UNIVERSITY \\ UNIVERSITY OF WASHINGTON
}

The Supporting Institutions listed above contribute to the cost of publication of this Journal, but they are not owners or publishers and have no responsibility for its content or policies.

Mathematical papers intended for publication in the Pacific Journal of Mathematics should be in typed form or offset-reproduced, (not dittoed), double spaced with large margins. Please do not use built up fractions in the text of the manuscript. However, you may use them in the displayed equations. Underline Greek letters in red, German in green, and script in blue. The first paragraph or two must be capable of being used separately as a synopsis of the entire paper. Please propose a heading for the odd numbered pages of less than 35 characters. Manuscripts, in triplicate, may be sent to any one of the editors. Please classify according to the scheme of Math. Reviews, Index to Vol. 39. Supply name and address of author to whom proofs should be sent. All other communications should be addressed to the managing editor, or Elaine Barth, University of California, Los Angeles, California, 90024.

50 reprints to each author are provided free for each article, only if page charges have been substantially paid. Additional copies may be obtained at cost in multiples of 50 .

The Pacific Journal of Mathematics is issued monthly as of January 1966. Regular subscription rate: $\$ 102.00$ a year (6 Vols., 12 issues). Special rate: $\$ 51.00$ a year to individual members of supporting institutions.

Subscriptions, orders for numbers issued in the last three calendar years, and changes of address shoud be sent to Pacific Journal of Mathematics, P.O. Box 969, Carmel Valley, CA 93924, U.S.A. Old back numbers obtainable from Kraus Per!odicals Co., Route 100, Millwood, NY 10546.

\section{PUBLISHED BY PACIFIC JOURNAL OF MATHEMATICS, A NON-PROFIT CORPORATION}

Printed at Kokusai Bunken Insatsusha (International Academic Printing Co., Ltd.). 8-8, 3-chome, Takadanobaba, Shinjuku-ku, Tokyo 160, Japan.

Copyright (C) 1981 by Pacific Jounal of Mathematics Manufactured and first issued in Japan 


\section{Pacific Journal of Mathematics}

Vol. 94, No. $2 \quad$ June, 1981

Thomas E. Armstrong and William David Sudderth, Nearly strategic

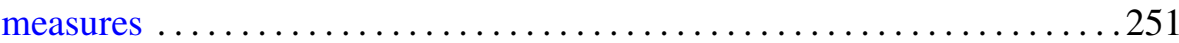

John J. Buoni, Artatrana Dash and Bhushan L. Wadhwa, Joint Browder

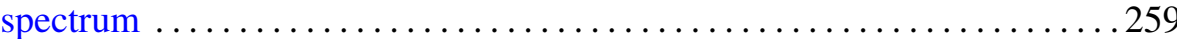

Jack Paul Diamond, Hypergeometric series with a $p$-adic variable . .......265

Raymond Frank Dickman, Jack Ray Porter and Leonard Rubin,

Completely regular absolutes and projective objects ............ 277

James Kenneth Finch, On the local spectrum and the adjoint ........... 297

Benno Fuchssteiner, An abstract disintegration theorem ............ 303

Leon Gerber, The volume cut off a simplex by a half-space $\ldots \ldots \ldots \ldots 311$

Irving Leonard Glicksberg, An application of Wermer's subharmonicity

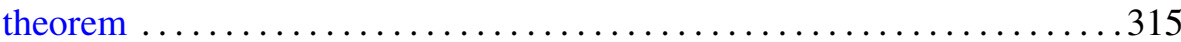

William Goldman, Two examples of affine manifolds ............... 327

Yukio Hirashita, On the Weierstrass points on open Riemann surfaces .....331

Darrell Conley Kent, A note on regular Cauchy spaces ............. 333

Abel Klein and Lawrence J. Landau, Periodic Gaussian

Osterwalder-Schrader positive processes and the two-sided Markov

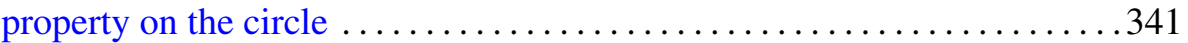

Brenda MacGibbon, $\mathscr{K}$-Borelian embeddings and images of Hausdorff

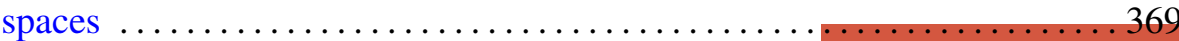

John R. Myers, Homology 3-spheres which admit no PL involutions . . . . . 379

Boon-Hua Ong, Invariant subspace lattices for a class of operators . . . . . 385

Chull Park, Representations of Gaussian processes by Wiener processes . . . 407

Lesley Millman Sibner and Robert Jules Sibner, A sub-elliptic estimate

for a class of invariantly defined elliptic systems $\ldots \ldots \ldots \ldots \ldots \ldots .417$

Justin R. Smith, Complements of codimension-two submanifolds. III.

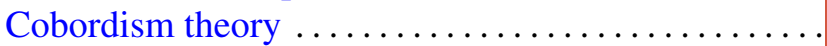

William Albert Roderick Weiss, Small Dowker spaces

David J. Winter, Cartan subalgebras of a Lie algebra and its ideals. II ... 